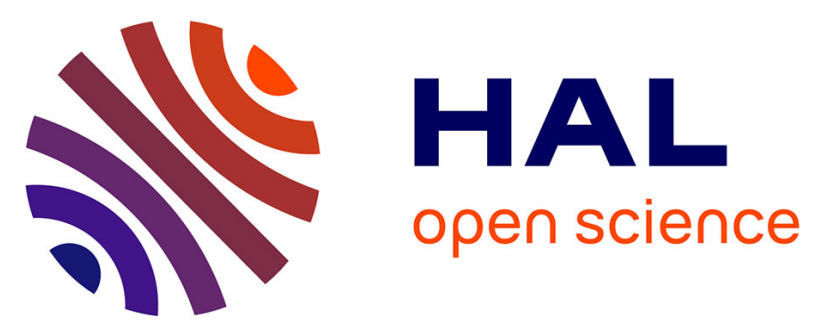

\title{
Plasma distribution of tetraphenylporphyrin derivatives relevant for Photodynamic Therapy: Importance and limits of hydrophobicity.
}

Benoît Chauvin, Athena Kasselouri, Bogdan I Iorga, Pierre Chaminade, Jean-Louis Paul, Philippe Maillard, Patrice Prognon

\section{To cite this version:}

Benoît Chauvin, Athena Kasselouri, Bogdan I Iorga, Pierre Chaminade, Jean-Louis Paul, et al.. Plasma distribution of tetraphenylporphyrin derivatives relevant for Photodynamic Therapy: Importance and limits of hydrophobicity.. European Journal of Pharmaceutics and Biopharmaceutics, 2013, 83, pp.244-252. 10.1016/j.ejpb.2012.09.015 . hal-00798420

\section{HAL Id: hal-00798420 \\ https://hal.science/hal-00798420}

Submitted on 7 Mar 2021

HAL is a multi-disciplinary open access archive for the deposit and dissemination of scientific research documents, whether they are published or not. The documents may come from teaching and research institutions in France or abroad, or from public or private research centers.
L'archive ouverte pluridisciplinaire HAL, est destinée au dépôt et à la diffusion de documents scientifiques de niveau recherche, publiés ou non, émanant des établissements d'enseignement et de recherche français ou étrangers, des laboratoires publics ou privés. 
2 Plasma distribution of tetraphenylporphyrin derivatives relevant for

3 Photodynamic Therapy: importance and limits of hydrophobicity

4

5

6

Author names and affiliations

Benoît CHAUVIN ${ }^{a, b}$, Athena KASSELOURI ${ }^{a}$, Bogdan IORGA ${ }^{c}$, Pierre CHAMINADE ${ }^{a}$, Jean-Louis PAUL ${ }^{\mathrm{d}, \mathrm{e}}$, Philippe MAILLARD ${ }^{\mathrm{b}}$, Patrice PROGNON ${ }^{\mathrm{a}}$

${ }^{a}$ Univ. Paris-Sud, EA 4041, IFR 141, Faculté de Pharmacie, F-92296 Châtenay-Malabry, France

${ }^{\mathrm{b}}$ Institut Curie, UMR 176 CNRS, Centre Universitaire, Univ Paris-Sud, F-91405 Orsay, France

${ }^{c}$ Institut de Chimie des Substances Naturelles, Gif sur Yvette, France

${ }^{d}$ AP-HP, Hôpital Européen Georges Pompidou, Service de Biochimie, Paris, France.

e Univ Paris-Sud, Laboratoire de Biochimie appliquée, EA 4529, 5 rue J-B. Clément, 92296 ChâtenayMalabry, France.

Benoît CHAUVIN : benoit.chauvin@u-psud.fr Athena KASSELOURI : athena.kasselouri@u-psud.fr Bogdan IORGA : bogdan.iorga@icsn.cnrs-gif.fr Pierre CHAMINADE : pierre.chaminade@u-psud.fr Jean-Louis PAUL : jean-louis.paul@u-psud.fr Philippe MAILLARD : philippe.maillard@curie.fr Patrice PROGNON : patrice.prognon@u-psud.fr

\section{Corresponding author}

Benoît CHAUVIN : benoit.chauvin@u-psud.fr

Laboratoire de Chimie Analytique, EA4041, IFR 141, Univ Paris-Sud, 5 rue J-B. Clément, 92296 Châtenay-Malabry, France

Tel: +33146835849

Fax: +33146835389

\section{Present/permanent address}

NA 


\section{Abstract}

In the course of a Photodynamic Therapy (PDT) protocol, desagregation of the sensitizer upon binding to plasma proteins and lipoproteins is one of the first step following intraveinous administration. This step governs its subsequent biodistribution, and has even been evoked as possibly orientating mechanism of tumor destruction. It is currently admitted as being mainly dependent on sensitizer's hydrophobicity. In this context, as far as glycoconjugation, a promising strategy to improve targeting of retinoblastoma cells, confers to the sensitizer an amphiphilic character, we have studied the effect of this strategy on binding to plasma proteins and lipoproteins. With the exception of the majoritary protein-binding (more than $\mathbf{8 0 \% )}$ of more hydrophilic para-tetraglycoconjugated derivatives, high-density lipoproteins (HDL) appear as main plasma carriers of the other amphiphilic glycoconjugated photosensitizers. This HDL-binding is a combined result of binding affinities (log Ka ranging from 4.90 to 8.77 depending on the carrier and the TPP derivative considered) and relative plasma concentrations of the different carriers. Evaluation of binding affinities shows that if hydrophobicity can account for LDL- and HDL-affinities, it is not the case for albumin-affinity. Molecular docking simulations show that, if interactions are mainly of hydrophobic nature, polar interactions such as hydrogen bonds are also involved. Those combination of interaction modalities should account for the absence of correlation between albumin-affinity and hydrophobicity. Taken together, our findings clarify the importance, but also the limits, of hydrophobicity's role in structure - plasma distribution relationship.

Keywords

meso-tetraphenylporphyrin, photodynamic therapy, plasma, lipoprotein, albumin, hydrophobicity 


\section{Abbreviations}

56 TPP : 5,10,15,20-tetraphenylporphyrin, meso-tetraphenylporphyrin

57 MCR-ALS : Multivariate Curve Resolution - Alternating Least Squares

58 PDT : PhotoDynamic Therapy

59 DEG : Di Ethylene Glycol

$60 \operatorname{TPP}(\mathrm{mOH})_{3}: 5,10,15$-tri-(meta-hydroxyphenyl)-20-phenylporphyrin

$61 \operatorname{TPP}(m \mathrm{OH})_{4}: \quad 5,10,15,20$-tetra-(meta-hydroxyphenyl)porphyrin

$62 \operatorname{TPP}(m \mathrm{O} \square \mathrm{GluOH})_{3}: 5,10,15$-tri-(meta-O- $\square$-D-glucopyranosyloxyphenyl)-20-phenylporphyrin

$63 \operatorname{TPP}(m \mathrm{O} \square \mathrm{GluOH})_{4}: 5,10,15,20$-tetra-(meta-O- $\square$-D-glucopyranosyloxyphenyl)porphyrin

$64 \operatorname{TPP}(p \mathrm{OH})_{3}: 5,10,15$-tri(para-hydroxyphenyl)-20-phenylporphyrin

$65 \operatorname{TPP}(p \mathrm{OH})_{4}: 5,10,15,20$-tetra-(para-hydroxyphenyl)porphyrin

$66 \operatorname{TPP}(p \mathrm{O} \square \mathrm{GalOH})_{3}: 5,10,15$-tri(para-O- $\square-\mathrm{D}$-galactosyloxyphenyl)-20-phenylporphyrin

$67 \operatorname{TPP}(p \mathrm{O} \square \mathrm{GalOH})_{4}: 5,10,15,20$-tetra-(para-O- $\square$-D-galactosyloxyphenyl)porphyrin

$68 \mathrm{TPP}(\mathrm{pO} \square \mathrm{GluOH})_{4}: 5,10,15,20$-tetra-(para-O- $\square-\mathrm{D}$-glucopyranosyloxyphenyl)porphyrin

$69 \operatorname{TPP}(p \mathrm{ODEGO} \square \mathrm{ManOH})_{3}:$ 5,10,15-tri\{para-O-[(2-(2-O- $\left.\square-D-m a n n o s y l o x y\right)$-ethoxy)-ethoxy]-phenyl\}-20-

70 phenylporphyrin 


\section{Introduction}

72 Photodynamic Therapy (PDT) is an emerging technique which combines administration of a 73 drug, called photosensitizer, and exposure of targeted tissue to light of appropriate wavelength. Treatment effect results from the potency of the photosensitizer once activated by light to generate singlet oxygen and radical species responsible for cellular death. PDT has already proven its efficacy in the field of oncology for the treatment of lung, gastrointestinal or cutaneous tumours. It has also be applied to non-malignant diseases such as age-related macular degeneration [1]. In that case, transparency of ocular tissues to light makes PDT of particular interest. This property should also been exploited for the treatment of malignant ocular pathologies, such as retinoblastoma, the most frequent intraocular tumor in childhood. Indeed, besides poor efficiency for advanced tumors, currently available conservative treatments expose patients to a risk of developing secondary tumors [2]. PDT appears as promising, combining a physical selectivity (tissular volume illuminated) and a chemical one (tissular volume containing the photosensitizer). When applied to retinoblastoma tumors, photosensitizers developed for other pathologies have shown poor efficiencies and selectivities, leading to side-effects such as long lasting photosensitization of normal tissues. Design of new photosensitizers adapted to retinoblastoma appears necessary [3].

Our group is involved in the evaluation of glycoconjugation of tetrapyrrolic macrocycles. This strategy combines targeting of cellular sugar receptors and improvement of photosensitizer solubility. The former promotes selective destruction of malignant cells, the latter favors rapid elimination from healthy tissues. In vitro photocytotoxicity and in vivo pharmacokinetics studies have confirmed the potential interest of this approach [4, 5]. Efficacity of a glycoconjugated TPP, TPP $(p O D E G O \square M a n O H)_{3}$, has been attested in vivo, especially with a particular administration protocol (double drug dose with a 3 hour interval), which combines targeting of cancer cells and of blood vessels. Indeed, at the time of illumination, drug administered 10 min before is still present in the vicinity of blood vessels whereas drug 
administered 3 hour before has reached tumor cells [6]. Destruction of blood vessels indirectly kills tumor tissue, through deprivation of oxygen and nutriments [7].

Photo-induced destruction of blood vessels is of particular interest in the case of an application of PDT to retinoblastoma as far as this tumor is considered as extremely sensitive to vascular insufficiency [8]. However, this possible mechanism of action rises the question of selectivity. This concept, defined as the ratio of sensitizer concentrations in tumor relative to healthy adjacent tissue, must not be considered as the exclusive result of tumor cells specificities. Tumor vasculature particularities could also be involved. Indeed, tumor angiogenesis leads to the formation of permeable neo-vessels [9]. However, Roberts has shown that this particular permeability is insufficient to account for selective retention of photosensitizers. Excluding a possible difference in lymphatic drainage, he formulated the hypothesis that selectivity results from a particular affinity of photosensitizers for endothelium of neo-vessels, presuming an implication of drug carriers, such as albumin and lipoproteins [10]. Binding to the latter has retained particular attention since the observation by Jori of a strong correlation between fraction of photosensitizer bound to LDL and selectivity [11]. Overexpression of LDL-receptors by tumor cells and also by endothelial cells reinforces this hypothesis [12]. If LDL-binding is associated to tumour cell delivery, binding of sensitizer to high density lipoprotein (HDL) or albumin has been associated with vascular sequestration of photosensitizer, leading to vascular damages upon photoactivation [13]. A strict correlation between binding to a carrier and localization remains difficult to establish, localization being time-dependent. Thus, biodistribution studies of BPD-MA conjugated to lipoproteins has shown the role of plasma carriers in modulation of pharmacokinetics: conjugation to LDL increases selectivity whereas conjugation to HDL delays tumor accumulation [14].

Plasma distribution studies have evidenced the major role of lipoproteins in photosensitizer transport, compared with the albumin binding of most drugs $[13,15]$. This particularity is attributed to the high hydrophobic character of sensitizers. This property seems to govern plasma distribution, as it is frequently considered that hydrophilic compounds bind to proteins (especially albumin) and lipophilic ones to LDL. Amphiphilic derivatives present a tendency to 
126 bind mainly to HDL [16]. In this point of view, glycoconjugation, which increases the solubility

127 of the sensitizer and decreases its hydrophobicity, should affect interactions with plasma 128 proteins and lipoproteins. Thus it appears essential to focus on the impact of the 129 glycoconjugation on drug distribution between plasma components. This study covers ten 130 meso-tetraphenylporphyrin derivatives, six of which are glycoconjugated according to 131 different modalities, and thus different lipophilicities. The aim is, beyond a description of the 132 relationship between structure and plasma distribution, to better understand factors 133 governing interactions of TPP sensitizers with plasma proteins and lipoproteins.

\section{$135 \quad$ 2. Materials and Methods}

\section{2.1. Chemicals}

$137 \operatorname{TPP}(p \mathrm{OH})_{4}$ was purchased from Sigma-Aldrich ${ }^{\circledR}$ (Germany) and TPP $(m \mathrm{OH})_{4}$ from Frontier 138 Scientific $^{\circledR}$ (USA). All other porphyrins were synthesized according to previously published 139 protocols [17-20]. Stock solutions were prepared in DMSO and kept in the dark at $+4^{\circ} \mathrm{C}$.

140 Theophylline, 5-phenyl-1H-tetrazole, indole, propiophenone and valerophenone were 141 provided by Acros Organics (USA), benzimidazole, butyrophenone, colchicine, potassium

142 bromide and ammonium acetate by Merck (Germany), acetophenone by Carlo Erba (Italia), $1430.9 \%$ sodium chloride solution by Aguettant (France). HPLC grade acetonitrile, methanol 144 and dimethylsulfoxyde came from VWR (Germany), $\mathrm{pH}$ 7.4 PBS and human serum albumin 145 from Sigma-Aldrich (Germany). Two different references of the latter (corresponding to 146 different purification levels) were used, one is essentially fatty acid free (HSA), the other is 147 not fatty acid free (HSAlip). Ultrapure water was provided by an Alpha-Q device (Millipore ${ }^{\circledR}$, 148 France). Human plasma was taken from normolipemic hemochromatosis patients.

\section{$150 \quad$ 2.2. Determination of Chromatographic Hydrophobicity Index (CHI)}

151 The procedure proposed by Valko has been applied to the TPP derivatives [21]. CHI values 
set covered the log $\mathrm{P}$ range from -0.02 to 3.26 : theophylline, 5-phenyl-1H-tetrazole,

154 benzimidazole, colchicine, 8-phenyltheophylline, indole, acetophenone, propiophenone, 155 butyrophenone, and valerophenone. HPLC measurements were performed on a Biotek 156 Kontron system, operated with Geminyx (version 1.91) software. Experiments were carried 157 out on a Modulo-cart QS uptisphere ODB column (Interchim, France), with the dimensions of $158150 \times 4.6 \mathrm{~mm}$. The mobile phase, a gradient between of $50 \mathrm{mM}$ ammonium acetate $(\mathrm{pH}$ 159 ranging from 7.0 to 7.3 ) and acetonitrile, was delivered at the flow rate of $1.0 \mathrm{~mL}^{\mathrm{min}}{ }^{-1}$ 160 according to the following program: $0-1.5 \mathrm{~min}, 0 \%$ acetonitrile; $1.5-10.5 \mathrm{~min}, 0-100 \%$ 161 acetonitrile; $10.5-11.5 \mathrm{~min}, 100 \%$ acetonitrile; $11.5-12.0 \mathrm{~min}, 0 \%$ acetonitrile; $12.0-20.0 \mathrm{~min}$,

$1620 \%$ acetonitrile. For every TPP studied, reference dataset was injected simultaneously with 163 the photosensitizer in a mixture of $50 \%$ acetonitrile and $50 \%$ aqueous ammonium acetate 164 buffer. Elution of the standards and of the photosensitizer were monitored respectively at 254 $165 \mathrm{~nm}$ and $416 \mathrm{~nm}$. Final $\mathrm{CHI}$ values for TPPs were the mean of three experiments, using $\mathrm{CHI}$ 166 values determined by Valko for reference dataset.

\subsection{Distribution in human plasma}

169 After 24-hour incubation with one percent of a porphyrin solution in dimethylsulfoxide, plasma 170 samples were brought to the density of $1.21 \mathrm{~g} \cdot \mathrm{mL}^{-1}$ with potassium bromide. Porphyrin final 171 molar concentration $(3 \mu \mathrm{M})$ was in the order of magnitude of what should be expected in vivo 172 with an effective dose. Protein and lipoprotein fractions were separated by ultracentrifugation 173 (90 $000 \mathrm{rpm}, 8 \mathrm{~h}, 4^{\circ} \mathrm{C}$ ) using a Beckman NVT 90 rotor in a Beckman XL 90 ultracentrifuge.

174 Separation of lipoproteins was performed with a density-gradient ultracentrifugation using a 175 five-step $\mathrm{KBr} / \mathrm{NaCl}$ gradient (densities of $1.063,1.042,1.019$ and $1.006 \mathrm{~g} \cdot \mathrm{mL}^{-1}$ on top of 176 plasma and a $1.21 \mathrm{~g} \cdot \mathrm{mL}^{-1} \mathrm{KBr}$ solution) and centrifuging for $24 \mathrm{~h}\left(38000 \mathrm{rpm}, 4^{\circ} \mathrm{C}\right)$ using a 177 Beckman SW 41 rotor in a Beckman XL 90 ultracentrifuge. After ultracentrifugation, fractions 178 were collected using a system including a Density Gradient Fractionator ISCO Model 185, a 179 collector LKB Bromma - 2212 HELIRAC and a detector LKB Bromma - 2238 UVICORD S II 180 (continuous absorbance monitoring at $280 \mathrm{~nm}$ ). An extraction was performed on the samples 
181 according to the method proposed by Wang [22]. $1900 \mu \mathrm{L}$ of a mixture dimethylsulfoxide -

182 methanol $1: 4(\mathrm{v} / \mathrm{v})$ was added to $100 \mu \mathrm{L}$ of each fraction collected. After centrifugation (10

$183 \mathrm{~min}, 4000 \mathrm{rpm}$ ), fluorescence intensity was read on the supernatant with a Perkin-Elmer LS-

184 50B spectrofluorimeter, with an excitation wavelength set at $420 \mathrm{~nm}$. Plasma distribution

185 between the different fractions was calculated on the basis of those fluorescence intensities.

186

187 2.4. Spectroscopic study of interactions with plama proteins and lipoproteins

188 2.4.1. Preparation of $L D L$ and $H D L$ fractions

189 Human plasma density is adjusted to $1.019 \mathrm{~g} \cdot \mathrm{mL}^{-1}$ with $\mathrm{KBr}$. After $24 \mathrm{~h}$ centrifuging (45 000

$\left.190 \mathrm{rpm}, 4^{\circ} \mathrm{C}\right)$, supernatant is removed and density of the remaining is further increased to

$1911.063 \mathrm{~g} \cdot \mathrm{mL}^{-1}$ with $\mathrm{KBr}$. After $48 \mathrm{~h}$ centrifuging $\left(45000 \mathrm{rpm}, 4^{\circ} \mathrm{C}\right)$, two fractions are obtained,

192 the upper one corresponding to LDL, the lower one to HDL. Molar concentrations of LDL and

193 HDL particles were determined on the basis of apoprotein quantitation according to the

194 method proposed by Ohnishi [23].

195 2.4.2. Sample preparation and conditions of spectra recording

196 An intermediate dilution of TPP stock solutions in $\mathrm{pH} 7.4$ phosphate buffer saline (PBS) was

197 used to prepare mixtures of a TPP with the studied plasma carrier (HSA, HSA-LIP, HDL ou

198 LDL). Dimethylsulfoxide final proportion in this solution was $0.5 \%$. TPP final concentration

199 was $1.10^{-7} \mathrm{M}$ for fluorescence measurements and $5.10^{-7} \mathrm{M}$ for absorption study. Transporter

200 concentration varied from 0 to $1.10^{-4} \mathrm{M}$. The mixtures were kept in darkness at $37^{\circ} \mathrm{C}$ for 24

201 hours. UV - Visible absorption spectra were recorded on a Varian ${ }^{\circledR}$ Cary Bio 100

202 spectrophotometer (Australia), with an optical path of $10 \mathrm{~mm}$ and a slit width of $2 \mathrm{~nm}$.

203 Fluorescence emission spectra were recorded with a Perkin-Elmer LS-50B

204 spectrofluorimeter, with an excitation wavelength set at $420 \mathrm{~nm}$ (excitation and emission slits 205 equal to $7 \mathrm{~nm})$.

206 2.4.3. Determination of binding constants 
207 When compared with absorption spectroscopy, determination of binding constants by 208 fluorimetry presents two advantages: the possibility of working with lower TPP concentrations $209\left(\sim 10^{-7} \mathrm{M}\right)$ than with absorption spectroscopy $\left(\sim 5.10^{-7} \mathrm{M}\right)$, and the lower diffusion due to 210 plasma carriers. Combined together, those two advantages widen the TPP - carrier ratio 211 range possible to study. Classical binding of drugs to plasma proteins and lipoproteins is 212 described by an equilibrium involving the free drug, the free carrier on the one side and the 213 drug-carrier complex on the other side. Thus, if binding involves a change in drug 214 fluorescence intensity at one wavelength, affinity constants can be determined through 215 monitoring of fluorescence at this wavelength:

$$
F=F_{\text {free }}+\left(F_{\text {bound }}-F_{\text {free }}\right) \times \frac{K_{a} \times[\text { Carrier }]}{1+K_{a} \times[\text { Carrier }]}(1)
$$

217 where $F_{\text {free }}$ and $F_{\text {bound }}$ are fluorescence emission intensities respectively of the free and of the 218 bound drug, [Carrier] the concentration of the drug carrier and $\mathrm{K}_{\mathrm{a}}$ the affinity constant defined 219 by the following relationship:

$$
K_{a}=\frac{[\text { Drug }- \text { Carrier }]}{[\text { Drug }][\text { Carrier }]}
$$

221 where $[$ Drug] and [Drug - Carrier $]$ are the respective concentrations of the free drug and of 222 the drug-carrier complex. This method relies on the proportionnality of $F_{\text {free }}$ and $F_{\text {bound }}$ to the 223 respective concentrations of these two forms, [Drug] and [Drug - Carrier]. However, in the 224 particular case of TPP derivatives, this is not the case. Indeed, free drug is not an 225 homogeneous form and covers in fact two different forms: an aggregated one (poorly 226 fluorescent) and a solubilized one (moderately fluorescent).Then, fluorescence intensity of 227 the free drug is no more directly proportional to its concentration, because it will depend on 228 its agregation rate, which is probably inversely related with its concentration.

229 To overcome limitations of monowavelength monitoring in this particular case, multivariate 230 curve resolution - alternating least squares (MCR-ALS) has been applied on fluorescence 231 emission spectra recorded with different carrier concentrations [24]. MCR-ALS consists in the 232 decomposition of this data matrix (D) into the product of two matrices: 1) a C matrix 
233 containing concentration profiles of the different species, 2) a S matrix with their fluorescence 234 spectra.

$$
D=C \cdot S^{\top}+E(3)
$$

236 E matrix represents difference between experimental values and data predicted by the 237 model, that is residuals. Data analysis method proposed by Diewok for MatLab [25] has been 238 adapted here to R software [26]. Optimization is based on als algorithm contained in the ALS 239 package [27]. High agregation of certain TPP derivatives combined with a strong affinity for 240 some of the studied plasma carriers reduces contribution of the solubilized drug. In as far as 241 fluorescence emission spectra of this particular species are the same whatever the carrier 242 considered, a column-wise extended approach has been used to improve results. D matrix is 243 constituted by spectra recorded on one TPP derivative with the four carriers studied : HSA, 244 HSAlip, LDL, HDL. C and S matrices respectively contain concentration and spectra profiles 245 of five species : the free solubilized drug and the four complexes formed by the TPP with 246 each of the four carriers studied. Because of its poor fluorescence, the aggregated free drug 247 is not included directly. Its presence is taken into account by applying no concentration 248 closure constraint (sums of concentrations of the other species at each carrier concentration 249 are not forced to be equal to one). For each carrier, concentration profile of the bound drug is 250 adjusted to follow relationship (2), before subsequent spectra optimization. When further 251 optimizations no more reduce residues' amount, the four binding constants are determined 252 by non-linear regression of the concentration profile with equation (2).

\section{$254 \quad$ 2.5. Molecular docking simulations}

255 Blind docking of TPP derivatives into human serum albumin (PDB code 1AO6) was 256 performed with AutoDock Vina 1.0 (exhaustiveness value of 100 and maximum output of 20 257 structures) [28]. Unsubstituted TPP crystal structure has been downloaded from the 258 Cambridge Structural Database (MOLFEZ). After substituents' addition with UCSF Chimera, ligands were prepared for docking using AutoDock Tools to calculate Gasteiger charges and

260 set active torsions (the four bonds between porphyrin core and phenyls, all rotatable bonds 
261 between the phenyl and the sugar residue). UCSF Chimera was used to visualize dockings, 262 calculate contact surfaces and monitor hydrogen bonds. The selection of the main binding 263 depended on the frequence of the different sites among the twenty output structures.

\section{Results}

\subsection{Hydrophobicity of TPPs}

267 As expected, glycoconjugation induces a decrease of hydrophobicity relative to the 268 hydroxylated parent compound. Moreover, hydrophobicity is further reduced with increasing 269 number of sugar residues. If these conclusions apply both to para and meta series, it is to 270 note that para-derivatives are less hydrophobic than their meta isomers. Thus, $\mathrm{CHI}$ of $271 \mathrm{TPP}(p \mathrm{O} \square \mathrm{GluOH})_{4}(28.3)$ is lower than that of the $\operatorname{TPP}(m \mathrm{mO} \square \mathrm{GluOH})_{4}$ (39.3). This also holds 272 true for hydroxylated compounds, when comparing $\operatorname{TPP}(p O H)_{4}(\mathrm{CHI}=100.2)$ and $\operatorname{TPP}(m O H)_{4}$ 273 (117.2). Because of minor differences of hydrophobicity between mannose and galactose 274 residues, the large $\mathrm{CHI}$ increase between $\operatorname{TPP}(p \mathrm{O} \square \mathrm{GalOH})_{3} \quad(\mathrm{CHI}=40.8)$ and $275 \operatorname{TPP}(p \mathrm{ODEGO} \square \mathrm{ManOH})_{3} \quad(\mathrm{CHI}=62.4)$ should be attributed to the presence of a spacer 276 between the sugar and the phenyle. The para-derivative with the spacer is even more 277 hydrophobic than the meta-triglycoconjugated derivative, $\operatorname{TPP}(m \mathrm{O} \square \mathrm{GluOH})_{3}(\mathrm{CHI}=55.7)$.

\subsection{Distribution in human plasma}

280 For eight of the ten studied compounds, more than $75 \%$ of the sensitizer is found in 281 lipoproteic fraction. Exceptions to this rule are constituted by the two para282 tetraglycoconjugated derivatives, $\operatorname{TPP}(p \mathrm{G} \square \mathrm{GalOH})_{4}$ and $\operatorname{TPP}(p \mathrm{O} \square \mathrm{GluOH})_{4}$, lone compounds 283 to be mainly bound - about $80 \%$ - to the proteic fraction. This behavior is particular striking 284 when compared with the quite exclusive lipoproteic transport of the meta285 tetraglycoconjugated derivative. Among compounds majoritary bound to lipoproteins, the 286 para-triglycoconjugated $\operatorname{TPP}(p \mathrm{O} \square \mathrm{GalOH})_{3}$ presents a significantly higher protein-bound 287 fraction than other compounds, including TPP $(p \mathrm{ODEGO} \square \mathrm{ManOH})_{3}$. Drug binding to proteic 
288 fraction concerns one quarter of the former but is negligeable in the case of the latter (less 289 than 6\%). This comparison shows that inclusion of a spacer between the sugar and the 290 phenyle has a dramatic effect on plasma distribution.

$291 \mathrm{HDL}$ are main lipoproteic carriers of photosensitizers. Indeed, with the exception of $292 \operatorname{TPP}(p \mathrm{O} \square \mathrm{GalOH})_{4}$ and $\operatorname{TPP}(p \mathrm{O} \square \mathrm{GluOH})_{4}$, those structures bind more than half of sensitizer 293 present in plasma. Binding to LDL is always minoritary, the highest proportion being reached 294 with the $\operatorname{TPP}(m \mathrm{mO} \square \mathrm{GluOH})_{4}$.

\subsection{Binding constants toward plasma proteins and lipoproteins}

297 Binding of TPPs to plasma carriers induces spectral modifications, accounting for the 298 disruption of TPPs aggregates upon formation of a complex between the TPP and the 299 carrier. Those equilibria can be followed by absorption or fluorescence spectroscopies. In the 300 absence of plasma carrier, absorption spectrum of $\operatorname{TPP}(p \mathrm{O} \square \mathrm{GalOH})_{3}$ presents a large Soret band at $417 \mathrm{~nm}$, with a distinct shoulder at $437 \mathrm{~nm}$, the latter resulting from the formation of

302 J-aggregates. HSA addition leads to the disappearance of the 437-nm shoulder 303 characteristic of aggregates, and to the appearance of a new intense band at $422 \mathrm{~nm}$, which 304 attests for the formation of the complex. Concerning fluorescence spectroscopy, binding of 305 TPP to HSA induces a slight modification of spectral shape but a significant increase in 306 fluorescence intensity.

307 If all TPP are likely to bind to LDL, HDL and HSA, affinities dramatically vary according to 308 carrier and substitution of the TPP core. However, it is remarkable to observe that, whatever 309 the TPP considered, affinities towards the different plasma carriers decrease when passing 310 from LDL to HDL and finally to HSA (whether fatty acid free or not). Even compounds mainly 311 bound to proteins in plasma $\left(\mathrm{TPP}(p \mathrm{G} \square \mathrm{GalOH})_{4}\right.$ and $\left.\operatorname{TPP}(p \mathrm{O} \square \mathrm{GluOH})_{4}\right)$ present a higher 312 affinity for LDL than for other studied plasma components. Those para-derivatives present 313 higher affinity constants towards HSA and HSAlip than their meta-homologous, an observation that applies whatever the substitution considered. 
315 An other noteworthy result is the large difference in binding affinities for compounds with

316 similar plasma distribution. That is the case of $\operatorname{TPP}(p O H)_{4}$ and $\operatorname{TPP}(p \mathrm{ODEGO} \square \mathrm{ManOH})_{3}$,

317 two compounds bound at $\sim 85 \%$ to HDL. Binding affinity to LDL and HSA is ten-fold higher

318 for the former than for the latter. When compared with $\operatorname{TPP}(p \mathrm{O} \square \mathrm{GalOH})_{3}$,

$319 \operatorname{TPP}(p \mathrm{ODEGO} \square \mathrm{ManOH})_{3}$ presents the same order of magnitude in their binding constants

320 towards LDL and HDL. Spacer mainly affects binding to HSA, decreasing ten fold binding

321 affinities, which could account for the lower protein binding of this compound when compared

322 with $\operatorname{TPP}(p \mathrm{O} \square \mathrm{GalOH})_{3}$.

\section{$324 \quad$ 3.4. Molecular docking simulations}

325 Depending on their substitution, TPPs interact at different locations on the HSA molecule.

326 The most noticeable result is the impossibility for those bulky structures to insert into the two

327 hydrophobic pockets that constitute Sudlow binding sites common to most drugs. It is difficult

328 to privilegiate one binding site for non-glycoconjugated TPPs. Those structures are spread at

329 different locations depending on their substitution. On the opposite, glycoconjugated

330 porphyrins present preferential clusters.

331 If considering glycoconjugated porphyrins, the most noticeable result is the drastic effect of

332 sugar position. Sugar nature and number don't seem to affect binding location. The two meta

333 derivatives, $\operatorname{TPP}(m \mathrm{O} \square \mathrm{GluOH})_{3}$ and $\operatorname{TPP}(m \mathrm{O} \square \mathrm{GluOH})_{4}$, bind on the same location in the

334 inter-domain crevice whereas the three para derivatives without spacer share the same

335 binding site. For the latter three compounds, $\operatorname{TPP}(p \mathrm{O} \square \mathrm{GalOH})_{3}, \operatorname{TPP}(p \mathrm{O} \square \mathrm{GalOH})_{4}$ and

$336 \operatorname{TPP}(p \mathrm{O} \square \mathrm{GluOH})_{4}$, the tetrapyrrole is located between residues Q104 and K466, with two

337 phenyles of both sides of residue K106.

$338 \operatorname{TPP}(\mathrm{mO} \square \mathrm{GluOH})_{3}$ binds between subdomains $\mathrm{lb}$ and IIla, with the TPP core located below 339 residue $\mathrm{R} 114$. The three sugar residues insert into three polar pockets: $\mathrm{i})$ the first formed by 340 residues $\mathrm{R} 114, \mathrm{R} 117, \mathrm{R} 186$ and $\mathrm{K} 519$, ii) the second constituted by residues N109, S419, 341 T422, K466 and T467, iii) the third composed by amino acids D108, H146, K190, R197 and 
342 Q459. In the case of the tetraglycoconjugated TPP $(m \mathrm{mO} \square \mathrm{GluOH})_{4}$, three sugars insert in the

343 same pockets, the fourth interacting with K524.

344 Of particular interest is the modulation of distribution pattern induced by the presence of the 345 spacer. If this particularity doesn't prevent TPP $(p O D E G O \square M a n O H)_{3}$ from interacting at the 346 same location than $\left.\operatorname{TPP}(p \mathrm{O} \square \mathrm{GalOH})_{3}\right)$, it favors binding on a site next to that of $347 \operatorname{TPP}(\mathrm{mO} \square \mathrm{GluOH})_{3}$, on a site inacessible to the tri-paraglycoconjugated derivative without 348 spacer $\left(\mathrm{TPP}(p \mathrm{O} \square \mathrm{GalOH})_{3}\right)$. In this particular conformation, the tetrapyrrole is close to 349 residue $\mathrm{P} 421$, one sugar is located between residues Q33 and E86, one other between 350 residues $\mathrm{K} 419$ and $\mathrm{K} 500$. The last mannose residue inserts into the third polar pocket 351 described for $\operatorname{TPP}(m \mathrm{O} \square \mathrm{GluOH})_{3}$.

352 The fact that sugar residues are suceptible to insert into polar pockets in the case of $353 \operatorname{TPP}(p \mathrm{ODEGO} \square \mathrm{ManOH})_{3}$ or meta-derivatives results in an higher contribution of the 354 substituent in the interaction surface for those derivatives (table 3). For those particular 355 structures, TPP ring is less accessible to solvent than in the case of para derivatives without 356 spacer. This latter fact is confirmed by the percentage of the TPP nucleus involved in the

357 interaction (table 3). Interaction surfaces increase with increasing surfaces of the TPP 358 derivatives. The main exception to this rule is para-tetraglycoconjugated derivatives, their 359 interface surfaces being lower than that of $\operatorname{TPP}(p \mathrm{O} \square \mathrm{GalOH})_{3}$. This fact probably results from 360 the rigidity of para-conformation, which induces a reduced possibility to insert into favorable 361 pockets upon increasing molecular volume. Indeed, flexibility of meta-derivatives confers to 362 those derivatives the ability to form higher interface surfaces with the protein than para 363 derivatives. Analysis of interaction modalities shows that TPPs interact with HSA mainly 364 through hydrophobic interactions but also through hydrogen bonds. The latter, which are 365 stronger interactions, mainly concern glycoconjugated compounds, due to their increased 366 number of hydroxyle groups.

368 4. Discussion

\subsection{Plasma distribution of photosensitizers}


370 Plasma distributions of glycoconjugated TPPs are consistent with common considerations on

371 the relationships between plasma distribution and hydrophobicity. Differences in

372 hydrophobicity mainly result from differences in exposure of the TPP ring due to the

373 presence of polar substituents. This principle accounts for the effect of substituent's nature

374 and number but also position. Indeed, para-substitution confers to the molecule a planar

375 conformation different from the globular conformation resulting from meta-substitution. The

376 latter allows an easier access to the hydrophobic TPP core.

377 Binding to the proteic fraction of para-tetraglycoconjugated derivatives can be explained by

378 the more pronounced hydrophilic character of those compounds. TPP $(p \mathrm{O} \square \mathrm{GalOH})_{3}$ presents

379 an intermediate $\mathrm{CHI}$ and an intermediate behavior between hydrophilic protein-bound

380 derivatives and more hydrophobic compounds quite exclusively bound to lipoproteins. The

381 latter compounds present the typical behavior of amphiphilic compounds, mainly bound to

382 HDL. Binding to LDL concerns always a minoritary proportion of TPPs on the studied series.

383 The effect of para-glycoconjugation appears similar to that of para-sulfonation as described

384 by Kongshaug [13]: only the tetrasubstituted compound binds mainly to proteins, other 385 derivatives (whether mono-, di- or tri-sulfonated) bind mainly to lipoproteins, majoritarily HDL.

386 Binding to LDL is commonly associated with the hydrophobic character of TPPs. However, in 387 our series, there is no correlation between proportion bound to LDL and CHI. This finding is 388 similar to that described in the case of the sulfonated TPPs : a disulfonated TPP presents a 389 higher proportion bound to LDL than the more hydrophobic monosulfonated derivative [13].

390 Moreover, in our series, similar hydrophobicities do not imply similar distribution patterns, as 391 can be evinced by comparing $\operatorname{TPP}(p \mathrm{O} \square \mathrm{GalOH})_{3}$ and $\mathrm{TPP}(m \mathrm{O} \square \mathrm{GluOH})_{4}$.

\section{4.2. From plasma distribution to binding constants}

394 The most striking conclusion of the comparison between plasma distribution and binding 395 constants is that even compounds predominantly bound to proteins in plasma have a higher 396 affinity towards lipoproteins, especially LDL. This striking result recalls that relative affinities 397 towards separated plasma carriers is just a part of its plasma distribution, the latter being 
398 also the result of relative concentrations of plasma carriers. Involvement of plasma protein

399 and lipoprotein concentrations has been underlined by Kongshaug in the case of 400 hematoporphyrin [29]. This compound presents a majoritary binding to HDL in plasma, 401 despite a higher affinity towards LDL than towards HDL. Thus, plasma distributions of $402 \operatorname{TPP}(p \mathrm{O} \square \mathrm{GalOH})_{4}$ and $\operatorname{TPP}(p \mathrm{O} \square \mathrm{GluOH})_{4}$ are not the consequence of a particular affinity 403 towards albumin, but the result of a ratio of affinities towards lipoproteins and albumin not 404 high enough to overcome the difference in the concentrations of those carriers. Indeed, 405 albumin is the most abundant plasma protein $(\sim 0.5-0.8 \mathrm{mM})$ whereas lipoprotein 406 concentration is much lower ( 1 $\mu \mathrm{M}$ for $\mathrm{LDL}$ and $13 \mu \mathrm{M}$ for HDL).

407 Despite presumed protein-affinity of hydrophilic compounds, there is no correlation between 408 affinity towards HSA and $\mathrm{CHI}$. Hydrophilic compounds, such as TPP $(m \mathrm{mO} \square \mathrm{GluOH})_{4}$, present 409 low binding constants but it is also the case of most hydrophobic structures such as $410 \operatorname{TPP}(m \mathrm{mH})_{3}$. Highest binding constants are characteristic of compounds $\left(\mathrm{TPP}(p \mathrm{OH})_{4}\right.$, $411 \operatorname{TPP}(\mathrm{mOH})_{4}$ or $\left.\operatorname{TPP}(p \mathrm{O} \square \mathrm{GalOH})_{3}\right)$ with intermediate hydrophobicities. On the contrary, TPPs' 412 affinity towards lipoproteins can be globally accounted for by their hydrophobicity. Affinity 413 increase with $\mathrm{CHI}$ applies both to HDL and LDL but is more pronounced in the case of the 414 latter. This observation can be linked to the classical idea of a preferential binding of more 415 hydrophobic structures to LDL. However, this rule knows exceptions and in the studied 416 series, despite correlation of affinity with $\mathrm{CHI}$, proportion of LDL-binding is not correlated with 417 hydrophobicity. The latter fact is the consequence of the absence of correlation between 418 affinity towards $\mathrm{HSA}$ and $\mathrm{CHI}$.

419 Similar considerations should explain an exception to the classical rule reported by Hasan. 420 Protoporphyrin and hematoporphyrin bind in the same proportions to plasma proteins despite 421 the higher hydrophobicity of the former. This result must be viewed as the consequence of 422 the difference in substitution which confers a much higher affinity towards albumin for 423 protoporphyrin $\left(280.10^{6} \mathrm{M}^{-1}\right)$ than for hematoporphyrin $\left(1,4.10^{6} \mathrm{M}^{-1}\right)$. This albumin affinity 424 increase counterbalances the probable hydrophobicity-induced increase in affinity towards 425 lipoproteins, resulting in a similar plasma distribution. 


\section{4.3. Interactions with Human Serum Albumin}

428 Contrary to HDL- and LDL-affinities, an increase in hydrophobicity doesn't result in an

429 increased affinity towards albumin. Confronted with similar observations, some authors have 430 underlined the importance of the amphiphilic character of the photosensitizer in its 431 interactions with proteins [30]. Those conclusions strengthen the interest of docking 432 simulations to better understand phenomena governing interactions between TPPs and HSA. 433 Docking results have shown that substitution affects location of the TPP derivative on the 434 protein. Moreover, they have led to exclude interactions at classical drug binding sites I and 435 II, unlike what has been described for some sensitizers: chlorin p6, purpurin 18 [32] or 436 bacteriochlorin derivatives [33]. This difference probably results from steric difference 437 between those tetrapyrroles not bearing phenyles at meso positions and the bulky TPP core. 438 Results obtained with other tetra-parasubstituted TPPs conclude to a binding at the surface 439 of the albumin molecule, a result consistent with our findings. Fluorescence lifetime studies 440 performed on a series of sulfonated phthalocyanines have shown that degree of sulfonation 441 influences insertion in hydrophobic pockets. Tetrasulfonated derivative bind at the surface of 442 the protein whereas lower sulfonation degree allows insertion into hydrophobic cavities [34]. 443 However, effect of substituent is only partly steric. It also plays a role in interactions 444 modalities between sensitizer and HSA. Sulfone groups could form ionic interactions with 445 basic amino acids (histidine and lysine), an hypothesis strengthened by sensitivity of 446 interactions to ionic strength [35].

447 The double acting effect of the substituent, likely to form direct interactions with HSA but also 448 to induce steric limitations, also applies to our series of hydroxylated and glycoconjugated 449 porphyrins. Glycoconjugated derivatives form more hydrogen bonds than hydroxylated ones, 450 and meta-derivatives more than para-derivatives. However, even when glycoconjugated, 451 TPP derivatives interact with the protein mainly through hydrophobic interactions. The direct 452 involvement of the substituent in the binding distinguishes TPP interactions with proteins 453 from their interactions with the $\mathrm{C} 18$ surface in the HPLC experiments. Indeed, $\mathrm{CHI}$ values are 
454 highly correlated with ratios of TPP nucleus surface to the total TPP derivatives surface $\left(r^{2}=\right.$ 4550,94 when excluding the highly flexible $\left.\operatorname{TPP}(p \mathrm{ODEGO} \square \mathrm{ManOH})_{3}\right)$, which illustrates the 456 probable lack of direct interactions between the substituent and apolar surfaces. In the case 457 of interactions with albumin, susbtituents interact directly with the protein, especially if the 458 TPP derivative possesses some flexibility (case of meta-derivatives and $\left.459 \operatorname{TPP}(p \mathrm{ODEGO} \square \mathrm{ManOH})_{3}\right)$. Rigidity of planar para-derivatives prevents them to form specific 460 interactions with albumin, which could explain the absence of difference in distribution 461 pattern between $\operatorname{TPP}(p \mathrm{O} \square \mathrm{GalOH})_{4}$ and $\operatorname{TPP}(p \mathrm{O} \square \mathrm{GluOH})_{4}$ despite modification of the nature 462 of sugar residue. This observation also applies to the respective affinities of those particular 463 derivatives.

464 When compared with the more widespread distribution pattern of para-derivatives, meta465 derivatives seem to present stronger and more specific interactions. This result, conflicting at 466 the first sight with affinity constants (higher in the para series), should maybe be considered 467 differently: globular conformation of meta-derivatives prevents them from interacting at the 468 surface of albumin molecule, thus restraining their possible binding sites. In this perspective, 469 higher overall binding constants measured on para-derivatives could result from a higher 470 number of sites of almost equivalent affinities.

\section{$472 \quad$ 4.4. Considerations about the particular affinity for LDL}

473 Photosensitizers are likely to interact with lipoproteins according to two modes, whether with 474 the proteic portion and/or with the lipidic one [36]. Existence of high affinity sites on 475 apoprotein coexisting with secondary solubilization in lipidic portion has been supposed in 476 the case of interactions of chlorin e6 with LDL [37]. If global binding constant is of the same 477 order of magnitude than that obtained for glycoconjugated TPPs, a preferential binding to 478 apoprotein is unlikely for the latters. Good correlation between affinity towards lipoproteins 479 and hydrophobicity tend to privilegiate the idea of an interaction with the lipidic portion. It 480 seems probable that interactions of TPPs with the hydrophobic stationnary phase in HPLC 481 are quite similar to their interactions with the hydrophobic lipidic portion. Moreover, lower 
binding affinity towards lipoproteins of glycoconjugated derivatives - likely to interact strongly with proteic portion through hydrogen bonding - reinforces the hypothesis of an interaction with the lipidic portion. At last, this hypothesis is confirmed by comparison with affinities of TPPs towards liposomes [38]. Ranking of binding affinities towards those phospholipidic vesicules is close to that obtained with $\mathrm{HDL}$.

487 Difference in binding affinities towards HDL and LDL leads to consider a possible role of 488 certain lipids in the preferential binding of TPPs to LDL than HDL. Interactions of hypericin 489 with biological membranes have shown that this structure presents a particular affinity for 490 cholesterol [39], a fact that could account for its location in LDL, between hydrophobic core 491 and phospholipid shell [40]. Involving cholesterol is unlikely for our compounds, more amphiphilic than hypericin, and thus less able to insert deeply in the lipoprotein core. This 493 hypothesis is supported by studies of inclusion of dendrimeric porphyrins in biological 494 membranes, that show no impact of cholesterol proportion [41], contrary to what could have 495 been described for others photosensitizers, such as deuteroporphyrin [42]. Preferential 496 affinity for LDL than for HDL could result from differences in surface properties: LDL surface 497 is less hydrophobic and its outer layer is more fluid [43]. More hydrophobic character of HDL 498 surface results from the presence of more triglycerides and cholesterol esters in the outer 499 layer [44]. Combined together, amphiphilic structures could better interact with LDL, insertion 500 of hydrophobic pole being easier and interaction of hydrophilic part with the surface being 501 favored.

\section{Conclusion}

504 Those observations give a new insight in plasma distribution. Increasing hydrophobicity 505 should orientate distribution towards LDL, whereas lowering this parameter results in a 506 majoritary protein binding. Exceptions to this rule should result from specific interactions 507 between a photosensitizer and a carrier, interactions not directly related to its hydrophobicity. 508 Our study also shows that measuring the fraction bound to LDL is not sufficient to 509 understand the behavior of TPPs in plasma. Binding constant determinations are essential. If 
510 it is commonly admitted that plasma distribution plays a decisive role in orientating

511 biodistribution, binding affinities are likely to affect photosensitizer's ability to pass from the

512 carrier to its final target, a fact that should not be underestimateed when reconsidering the 513 link between plasma behavior and tumor localization.

514

$515 \quad 6 . \quad$ Acknowledgements

516

B. Chauvin has benefited from a "Postes d'accueil CNRS - CEA - APHP" grant. The authors thank technicians of HEGP Biochemistry service for their precious contribution to plasma distribution studies.

\section{References}

521 [1] T.J. Dougherty, C.J. Gomer, B.W. Henderson, G. Jori, D. Kessel, M. Korbelik, J. Moan, Q. 522 Peng, J. Natl. Cancer Inst, 90 (1998) 889-905.

[2] F. Doz, H. Brisse, D. Stoppa-Lyonnet, X. Sastre, J. Zucker, L. Desjardins, Retinoblastoma 524 in: Paediatric Oncology, Pinkerton, R Plowman, N Pieters, R, London, 2004.

525 [3] J.B. Winther, Acta Ophthalmol Suppl, (1990) 1-37.

526 [4] M.-C. Desroches, A. Bautista-Sanchez, C. Lamotte, B. Labeque, D. Auchère, R. Farinotti, P. Maillard, D.S. Grierson, P. Prognon, A. Kasselouri, J. Photochem. Photobiol. B, Biol, 85 (2006) 56-64.

529 [5] P. Maillard, B. Loock, D. Grierson, I. Laville, J. Blais, F. Doz, L. Desjardins, D. Carrez, J.

530 Guerquinkern, A. Croisy, Photodiagnosis and Photodynamic Therapy, 4 (2007) 261-268.

531 [6] M. Lupu, C.D. Thomas, P. Maillard, B. Loock, B. Chauvin, I. Aerts, A. Croisy, E. Belloir, A. 532 Volk, J. Mispelter, Photodiagnosis and Photodynamic Therapy, 6 (2009) 214-220.

533 [7] B. Chen, B.W. Pogue, P.J. Hoopes, T. Hasan, Int. J. Radiat. Oncol. Biol. Phys, 61 (2005) 534 1216-1226.

535 [8] M.R. Horsman, J. Winther, Acta Oncol, 28 (1989) 693-697.

536 [9] F. Danhier, O. Feron, V. Préat, Journal of Controlled Release, 148 (2010) 135-146.

537 [10] W.G. Roberts, T. Hasan, Cancer Res, 52 (1992) 924-930.

538 [11] G. Jori, L. Schindl, A. Schindl, L. Polo, Journal of Photochemistry and Photobiology A: 539 Chemistry, 102 (1996) 101-107.

540 [12] J.T.C. Wojtyk, R. Goyan, E. Gudgin-Dickson, R. Pottier, Medical Laser Application, 21 $541 \quad$ (2006) 225-238. 
542 [13] T. Hasan, B. Ortel, A.C. Moor, B.W. Pogue, dans: Cancer medicine 6, BC Decker, 543 Hamilton Ont. ;"Lewiston NY, 2003.

544 [14] B.A. Allison, P.H. Pritchard, A.M. Richter, J.G. Levy, Photochem. Photobiol, 52 (1990) $545 \quad 501-507$.

546 [15] H.J. Hopkinson, D.I. Vernon, S.B. Brown, Photochem. Photobiol, 69 (1999) 482-488.

547 [16] A.P. Castano, T.N. Demidova, M.R. Hamblin, Photodiagnosis and Photodynamic 548 Therapy, 2 (2005) 91-106.

549 [17] I. Laville, T. Figueiredo, B. Loock, S. Pigaglio, P. Maillard, D.S. Grierson, D. Carrez, A. 550 Croisy, J. Blais, Bioorg. Med. Chem, 11 (2003) 1643-1652.

551 [18] I. Laville, S. Pigaglio, J.-C. Blais, B. Loock, P. Maillard, D.S. Grierson, J. Blais, Bioorg. 552 Med. Chem, 12 (2004) 3673-3682.

553 [19] I. Laville, S. Pigaglio, J.-C. Blais, F. Doz, B. Loock, P. Maillard, D.S. Grierson, J. Blais, J. 554 Med. Chem., 49 (2006) 2558-2567.

555 [20] D. Oulmi, P. Maillard, J.-L. Guerquin-Kern, C. Huel, M. Momenteau, J. Org. Chem., 60 556 (1995) 1554-1564.

557 [21] K. Valko, C. Bevan, D. Reynolds, Anal Chem, 69 (1997) 2022-2029.

558 [22] Q. Wang, H.J. Altermatt, H.B. Ris, B.E. Reynolds, J.C. Stewart, R. Bonnett, C.K. Lim, 559 Biomed. Chromatogr, 7 (1993) 155-157.

560 [23] T. Ohnishi, N.A.L. Mohamed, A. Shibukawa, Y. Kuroda, T. Nakagawa, S. El Gizawy, 561 H.F. Askal, M.E. El Kommos, J Pharm Biomed Anal, 27 (2002) 607-614.

562 [24] A. de Juan, R. Tauler, Critical Reviews in Analytical Chemistry, 36 (2006) 163 - 176.

563 [25] J. Diewok, A. de Juan, M. Maeder, R. Tauler, B. Lendl, Anal. Chem., 75 (2003) 641-647.

564 [26] R Development Core Team, R: A Language and Environment for Statistical Computing, 565 R Foundation for Statistical Computing, Vienna, Austria, 2009.

566 [27] I.H. van Stokkum, K.M. Mullen, V.V. Mihaleva, Chemometr. Intell. Lab., 95 (2009) 150567163.

568 [28] O. Trott, A.J. Olson, J Comput Chem, 31 (2010) 455-461.

569 [29] M. Kongshaug, J. Moan, Int J Biochem Cell Biol, 21 (1995) 371-384.

570 [30] O. Rinco, J. Brenton, A. Douglas, A. Maxwell, M. Henderson, K. Indrelie, J. Wessels, J.

571 Widin, Journal of Photochemistry and Photobiology A: Chemistry, 208 (2009) 91-96.

572 [31] W. An, Y. Jiao, C. Dong, C. Yang, Y. Inoue, S. Shuang, Dyes and Pigments, 81 (2009) 573 1-9.

574 [32] S. Patel, A. Datta, J Phys Chem B, 111 (2007) 10557-10562.

575 [33] Y. Chen, R. Miclea, T. Srikrishnan, S. Balasubramanian, T.J. Dougherty, R.K. Pandey, 576 Bioorg. Med. Chem. Lett, 15 (2005) 3189-3192. 
577 [34] K. Lang, J. Mosinger, D.M. Wagnerova, Coordination Chemistry Reviews, 248 (2004) $578 \quad 321-350$.

579 [35] A. Filyasova, I. Kudelina, A. Feofanov, Journal of Molecular Structure, 565-566 (2001) $580 \quad 173-176$.

581 [36] S. Bonneau, C. Vever-Bizet, P. Morlière, J.-C. Mazière, D. Brault, Biophysical Journal, $58283(2002) 3470-3481$.

583 [37] H. Mojzisova, S. Bonneau, C. Vever-Bizet, D. Brault, Biochim. Biophys. Acta, 1768 584 (2007) 366-374.

585 [38] H. Ibrahim, A. Kasselouri, C. You, P. Maillard, V. Rosilio, R. Pansu, P. Prognon, Journal 586 of Photochemistry and Photobiology A: Chemistry, 217 (2011) 10-21.

587 [39] Y.-F. Ho, M.-H. Wu, B.-H. Cheng, Y.-W. Chen, M.-C. Shih, Biochimica et Biophysica 588 Acta (BBA) - Biomembranes, 1788 (2009) 1287-1295.

589 [40] G. Lajos, D. Jancura, P. Miskovsky, J. Garcia-Ramos, S. Sanchez-Cortes, Journal of 590 Physical Chemistry C, 113 (2009) 7147-7154.

591 [41] A. Makky, J.P. Michel, S. Ballut, A. Kasselouri, P. Maillard, V. Rosilio, Langmuir, 26 592 (2010) 11145-11156.

593 [42] K. Kuzelova, D. Brault, Biochemistry, 34 (1995) 11245-11255.

594 [43] J.B. Massey, H.J. Pownall, Biophys. J, 74 (1998) 869-878.

595 [44] L.S. Kumpula, J.M. Kumpula, M.-R. Taskinen, M. Jauhiainen, K. Kaski, M. Ala-Korpela, 596 Chem. Phys. Lipids, 155 (2008) 57-62. 
Figure 1. Structure of meso-tetraphenylporphyrin derivatives

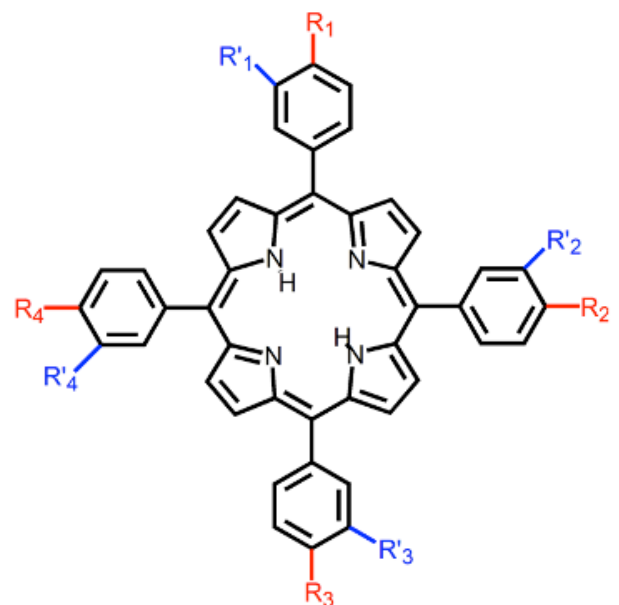

\begin{tabular}{|c|c|c|c|c|}
\hline \multicolumn{5}{|l|}{ meta-substituted compounds } \\
\hline$R_{1}=R_{2}=R_{3}=R_{4}=-H$ & $\mathbf{R}_{1}^{\prime}$ & $\mathrm{R}_{2}^{\prime}$ & $\mathrm{R}_{3}^{\prime}$ & $\mathrm{R}_{4}^{\prime}$ \\
\hline $\mathrm{TPP}(\mathrm{mOH})_{3}$ & $-\mathrm{OH}$ & $-\mathrm{OH}$ & $-\mathrm{OH}$ & $H$ \\
\hline $\mathrm{TPP}(m \mathrm{mOH})_{4}$ & $-\mathrm{OH}$ & $-\mathrm{OH}$ & $-\mathrm{OH}$ & $-\mathrm{OH}$ \\
\hline $\mathrm{TPP}(\mathrm{mO \beta GluOH})_{3}$ & -OBGIUOH & -OBGIUOH & $-\mathrm{O}$ OBGIUOH & H \\
\hline TPP(mOBGluOH), & -OBGIUOH & -OBGluOH & $-\mathrm{OBGluOH}$ & -OPGluOH \\
\hline \multicolumn{5}{|l|}{ para-substituted compounds } \\
\hline $\mathrm{R}_{1}^{\prime}=\mathrm{R}_{2}^{\prime}=\mathrm{R}_{3}^{\prime}=\mathrm{R}_{4}^{\prime}=-\mathrm{H}$ & $\mathrm{R}_{1}$ & $\mathrm{R}_{2}$ & $\mathrm{R}_{3}$ & $\mathrm{R}_{4}$ \\
\hline $\mathrm{TPP}(\mathrm{pOH})_{3}$ & $-\mathrm{OH}$ & $-\mathrm{OH}$ & $-\mathrm{OH}$ & H \\
\hline $\mathrm{TPP}(\mathrm{pOH})_{4}$ & $-\mathrm{OH}$ & $-\mathrm{OH}$ & $-\mathrm{OH}$ & $-\mathrm{OH}$ \\
\hline $\mathrm{TPP}(\rho \mathrm{O} / \mathrm{Ga} \mathrm{aH})_{3}$ & -OßGaЮH & -OßGalOH & $-\mathrm{O} G \mathrm{GaOH}$ & $H$ \\
\hline $\mathrm{TPP}(\mathrm{pO} / \mathrm{GGaOH})_{4}$ & -OßGaمH & -ORGaßH & -OBGaßH & -OpGaßH \\
\hline $\mathrm{TPP}(\mathrm{pO} / \mathrm{BGluOH})_{4}$ & -OBGIUOH & -OBGIUOH & $-\mathrm{OBGluOH}$ & -OpGluOH \\
\hline $\mathrm{TPP}(p \mathrm{ODEGO} \alpha \mathrm{ManOH})_{3}$ & -ODEGOaManOH & -ODEGOaManOH & -ODEGOaManOH & $H$ \\
\hline
\end{tabular}

600

601 Figure 2. Spectral modifications of $\operatorname{TPP}(p \mathrm{O} \square \mathrm{GalOH})_{3}$ upon binding to HSA

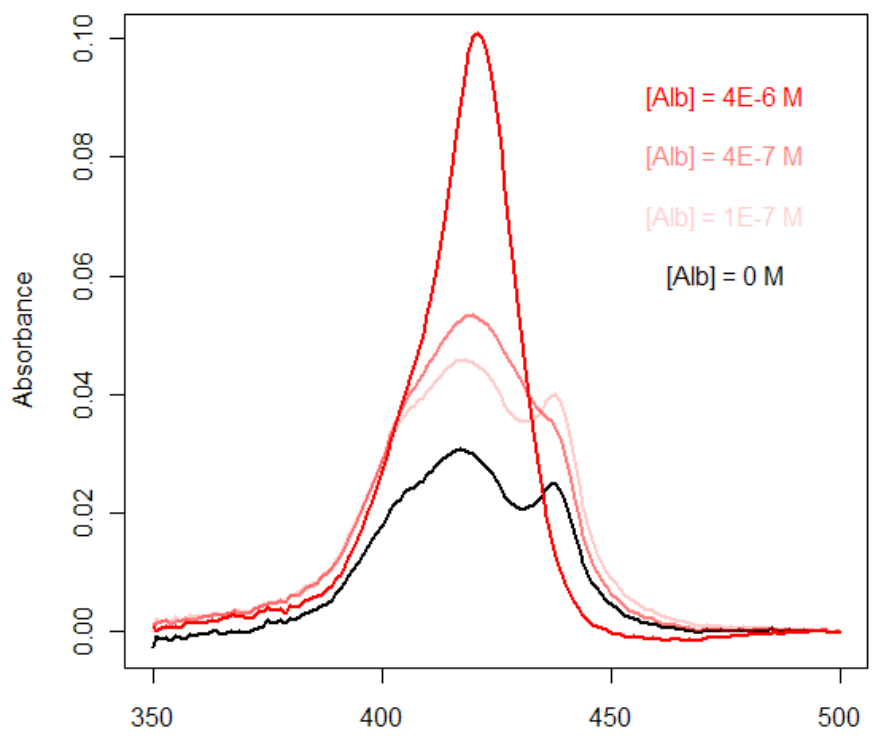


603 Figure 3. Conformations of meta- and para- derivatives

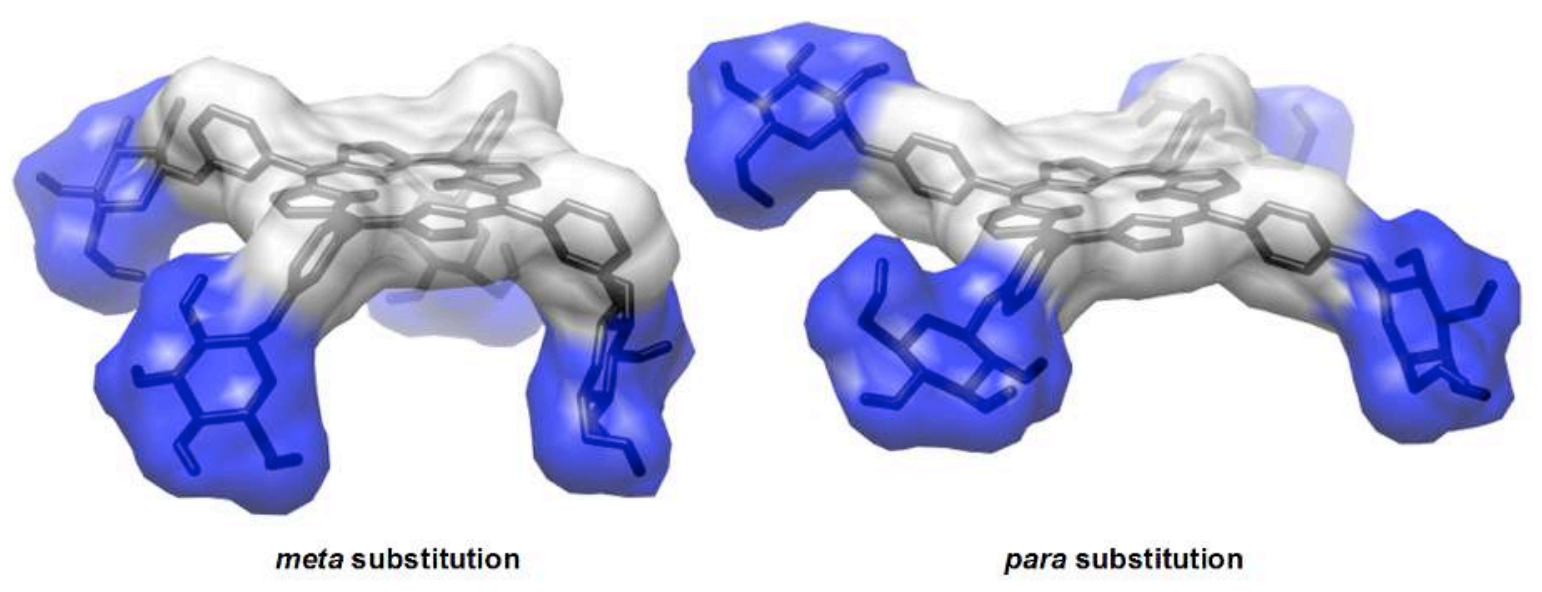

604

605

606 
Figure 4. Binding sites of glycoconjugated TPPs according to blind docking results

607

608

609

610

611

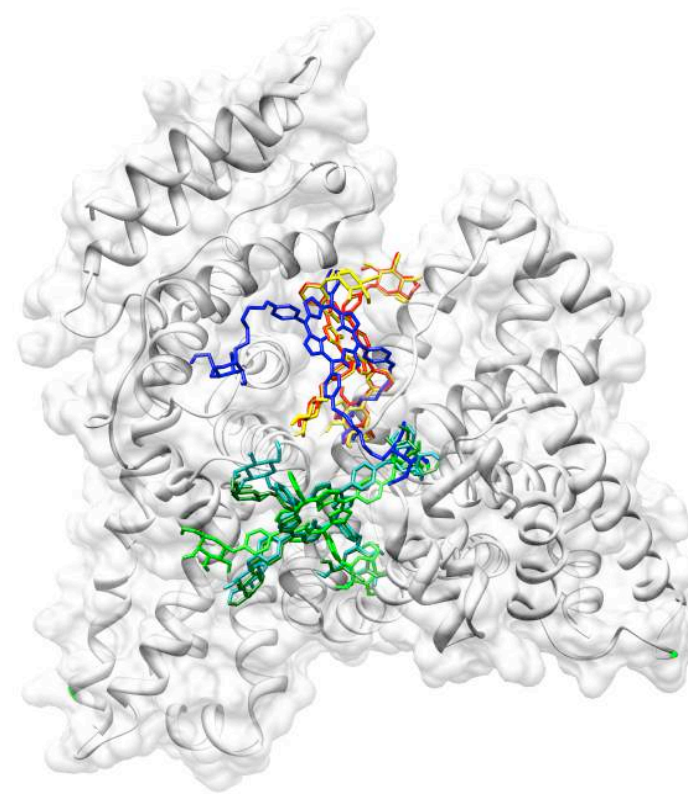

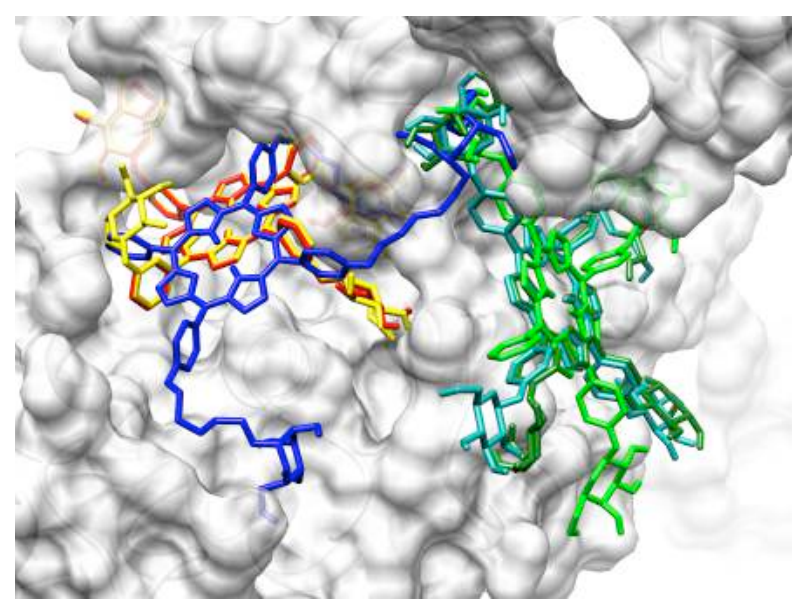

Binding sites of $\operatorname{TPP}(m \mathrm{mO} \square \mathrm{GluOH})_{3} \quad$ (in red), TPP $(m \mathrm{mO} \square \mathrm{GluOH})_{4} \quad$ (in yellow), $\operatorname{TPP}(p \mathrm{O} \square \mathrm{GalOH})_{3}$ (in green), TPP( $(p \mathrm{O} \square \mathrm{GalOH})_{4}$ (in dark green), TPP( $\left.p \mathrm{O} \square \mathrm{GluOH}\right)_{4}$ (in sea green) and TPP $(p O D E G O \square \mathrm{ManOH})_{3}$ (in blue)

Table 1. Plasma distribution of meso-tetraphenylporphyrin derivatives

\begin{tabular}{|l|c|c|c|c|c|}
\hline \multirow{2}{*}{ Compound } & & \multicolumn{3}{|c|}{ Lipoproteins } & \multirow{2}{*}{ Proteins } \\
\cline { 2 - 5 } & $\mathrm{CHI}$ & Total & HDL & LDL & \\
\hline $\operatorname{TPP}(m \mathrm{OH})_{3}$ & - & $94.7 \pm 1.3$ & $74.2 \pm 5.2$ & $17.3 \pm 4.8$ & $5.3 \pm 1.3$ \\
\hline $\operatorname{TPP}(m \mathrm{OH})_{4}$ & $117.2 \pm 0.1$ & $97.6 \pm 0.4$ & $71.3 \pm 1.0$ & $20.0 \pm 3.0$ & $2.4 \pm 0.4$ \\
\hline $\operatorname{TPP}(m \mathrm{~m} \square \mathrm{GluOH})_{3}$ & $55.7 \pm 0.5$ & $97.8 \pm 1.0$ & $78.0 \pm 4.9$ & $14.1 \pm 3.4$ & $2.2 \pm 1.0$ \\
\hline $\operatorname{TPP}(m \mathrm{mO} \square \mathrm{GluOH})_{4}$ & $39.3 \pm 0.1$ & $95.6 \pm 1.2$ & $60.8 \pm 13.0$ & $22.1 \pm 5.4$ & $4.4 \pm 1.2$ \\
\hline $\operatorname{TPP}(p \mathrm{OH})_{3}$ & - & $95.0 \pm 1.2$ & $77.6 \pm 4.7$ & $13.4 \pm 3.0$ & $5.0 \pm 1.2$ \\
\hline $\operatorname{TPP}(p \mathrm{OH})_{4}$ & $100.2 \pm 0.2$ & $96.4 \pm 1.3$ & $86.7 \pm 5.4$ & $7.7 \pm 4.0$ & $3.6 \pm 1.3$ \\
\hline $\operatorname{TPP}(p \mathrm{GalOH})_{3}$ & $40.8 \pm 0.1$ & $77.3 \pm 1.6$ & $67.7 \pm 2.1$ & $7.1 \pm 1.1$ & $22.7 \pm 1.6$ \\
\hline $\operatorname{TPP}(p \mathrm{G} \square \mathrm{GalOH})_{4}$ & $26.5 \pm 0.1$ & $10.4 \pm 1.4$ & $8.7 \pm 1.6$ & $1.4 \pm 0.5$ & $89.6 \pm 1.4$ \\
\hline $\operatorname{TPP}(p \mathrm{G} \square \mathrm{GluOH})_{4}$ & $28.3 \pm 0.1$ & $13.7 \pm 4.2$ & $11.3 \pm 3.6$ & $1.8 \pm 0.4$ & $86.3 \pm 4.2$ \\
\hline $\operatorname{TPP}(p \mathrm{ODEGO} \square \mathrm{ManOH})_{3}$ & $62.4 \pm 0.1$ & $95.4 \pm 1.3$ & $85.8 \pm 3.0$ & $8.6 \pm 4.0$ & $4.6 \pm 1.3$ \\
\hline
\end{tabular}


613 Table 2. Binding affinities of meso-tetraphenylporphyrin derivatives (expressed as $\log \mathrm{K}_{\mathrm{a}}$ )

\begin{tabular}{|l|c|c|c|c|c|}
\hline \multirow{2}{*}{ Compound } & \multirow{2}{*}{$\mathrm{CHI}$} & \multicolumn{2}{|c|}{ Albumin } & \multicolumn{2}{c|}{ Lipoproteins } \\
\cline { 3 - 6 } & & HSA & HSAlip & LDL & HDL \\
\hline $\operatorname{TPP}(m \mathrm{OH})_{3}$ & - & 5.07 & 5.50 & 8.30 & 8.11 \\
\hline $\operatorname{TPP}(p \mathrm{OH})_{3}$ & - & 5.60 & 5.77 & 8.32 & 7.11 \\
\hline $\operatorname{TPP}(m \mathrm{OH})_{4}$ & $117.2 \pm 0.1$ & 5.77 & 5.99 & 8.21 & 7.65 \\
\hline $\operatorname{TPP}(p \mathrm{OH})_{4}$ & $100.2 \pm 0.2$ & 6.32 & 6.17 & 8.77 & 7.35 \\
\hline $\operatorname{TPP}(p \mathrm{ODEGO} \square \mathrm{ManOH})_{3}$ & $62.4 \pm 0.1$ & 4.90 & 5.19 & 7.78 & 7.01 \\
\hline $\operatorname{TPP}(m \mathrm{O} \square \mathrm{GluOH})_{3}$ & $55.7 \pm 0.5$ & 5.66 & 5.73 & 7.64 & 7.33 \\
\hline $\operatorname{TPP}(p \mathrm{O} \square \mathrm{GalOH})_{3}$ & $40.8 \pm 0.1$ & 5.80 & 6.17 & 7.89 & 7.33 \\
\hline $\operatorname{TPP}(m \mathrm{O} \square \mathrm{GluOH})_{4}$ & $39.3 \pm 0.1$ & 5.05 & 5.03 & 7.58 & 6.95 \\
\hline $\operatorname{TPP}(p \mathrm{O} \square \mathrm{GluOH})_{4}$ & $28.3 \pm 0.1$ & 5.57 & 5.83 & 6.87 & 6.51 \\
\hline $\operatorname{TPP}(p \mathrm{G} \square \mathrm{GalOH})_{4}$ & $26.5 \pm 0.1$ & 5.29 & 5.27 & 6.80 & 6.33 \\
\hline
\end{tabular}

614

615 
616 Table 3. Properties of interface surfaces between HSA and the different TPP derivatives

\begin{tabular}{|c|c|c|c|c|c|}
\hline & \multicolumn{3}{|c|}{ Interface surface } & \multirow{2}{*}{$\begin{array}{l}\text { Percentage } \\
\text { of the TPP } \\
\text { surface } \\
\text { involved in } \\
\text { the } \\
\text { interaction }\end{array}$} & \multirow{2}{*}{$\begin{array}{c}\text { Contribution of } \\
\text { the substituent } \\
\text { in the } \\
\text { interaction }\end{array}$} \\
\hline & Polar & Apolar & Total & & \\
\hline TPP & 129.6 & 315.1 & 444.7 & $35.1 \%$ & $0.0 \%$ \\
\hline $\mathrm{TPP}(m \mathrm{O} \square \mathrm{GluOH})_{3}$ & 296.3 & 412.4 & 708.7 & $34.4 \%$ & $64.4 \%$ \\
\hline $\mathrm{TPP}(m \mathrm{O} \square \mathrm{GluOH})_{4}$ & 391.1 & 530.3 & 921.4 & $32.9 \%$ & $62.6 \%$ \\
\hline $\operatorname{TPP}(m O H)_{3}$ & 121.9 & 297.1 & 419.0 & $37.7 \%$ & $11.5 \%$ \\
\hline $\operatorname{TPP}(m \mathrm{OH})_{4}$ & 134.7 & 271.4 & 406.1 & $42.9 \%$ & $23.4 \%$ \\
\hline $\operatorname{TPP}(p \mathrm{O} \square \mathrm{GalOH})_{3}$ & 200.6 & 404.7 & 605.3 & $27.9 \%$ & $55.5 \%$ \\
\hline $\operatorname{TPP}(p \mathrm{O} \square \mathrm{GalOH})_{4}$ & 276.2 & 305.2 & 581.4 & $25.9 \%$ & $52.7 \%$ \\
\hline $\operatorname{TPP}(p \mathrm{O} \square \mathrm{GluOH})_{4}$ & 260.3 & 304.7 & 564.9 & $29.0 \%$ & $54.3 \%$ \\
\hline $\operatorname{TPP}(p \mathrm{OH})_{3}$ & 97.4 & 234.2 & 331.5 & $28.0 \%$ & $11.4 \%$ \\
\hline $\operatorname{TPP}(p \mathrm{OH})_{4}$ & 94.7 & 216.4 & 311.1 & $24.5 \%$ & $11.5 \%$ \\
\hline $\operatorname{TPP}(p O D E G O \square \mathrm{ManOH})_{3}$ & 352.9 & 464.5 & 817.4 & $30.6 \%$ & $69.5 \%$ \\
\hline
\end{tabular}

617 1. Defined as the ratio between the surface of the substituent in contact with the protein and 618 the total surface of the TPP derivative interacting with the protein 